\title{
The effects of Honey and Aloe Vera extract on Ibuprofen Induced Liver Damage in rats.
}

\author{
${ }^{1}$ A.M. Garba, ${ }^{2}$ B. Mohammed, ${ }^{3}$ S. H. Garba*, ${ }^{4}$ A. I. Numan, ${ }^{5}$ B. M. Dalori \\ ${ }_{1,2,3,4,5}$ Department of Human Anatomy, College of Medical Sciences, University of Maiduguri, Maiduguri \\ Nigeria.
}

\begin{abstract}
This study was designed to determine the effect of Aloe Vera extract and honey against ibuprofen induced liver damage in albino rats. A total of twenty five (25) adult male albino rats weighing 100-150g were divided into five groups (I, II, III, IV and V) of five rats each. Rats in group I served as control and were administered normal saline in a volume equivalent to the highest dosed group, rats in group II were administered 100mgkg-1 of ibuprofen, rats in group III were administered 100mgkg $\mathrm{m}^{-1}$ of ibuprofen and $10 \mathrm{gkg}^{-1}$ of Aloe Vera extract, rats in group IV were administered 100 $\mathrm{mgkg}^{-1}$ of ibuprofen and $10 \mathrm{gkg}^{-1}$ of honey while rats in group $V$ were administered with $100 \mathrm{mgkg}^{-1}$ of ibuprofen, $10 \mathrm{gkg}^{-1}$ of Aloe Vera extract and $10 \mathrm{gkg}^{-1} \mathrm{of}$ honey orally. The result showed a slight increase in liver weight, a significant increase $(P<0.05)$ in the levels of Aspartate minotransferases (ASAT), Alanine aminotransferases (ALAT) and Alkaline phosphatase (ALP) in the ibuprofen treated rats when compared to the control rats. Administration of Aloe vera extract and honey did not reverse the damage caused. Histological findings indicate severe dilation of blood vessel, necrosis of vascular connective tissues, wide spread vacuolar degeneration, edema and bile duct hyperplasia. The result indicates that Aloe vera extract and honey has little or no effect in preventing ibuprofen induced toxicity.
\end{abstract}

Key words: Honey, Aloe vera, Ibuprofen, Hepatotoxic, hyperplasia

\section{Introduction}

The liver being the largest internal organ in the body is always in close contact with many harmful substances thus generating interest in natural remedies that are particularly effective in either protecting the liver or curing it from many ailments caused by these toxins. Ibuprofen, belongs to a class of drugs called nonsteroidal anti-inflammatory drugs (NSAIDs) which are mostly and are used for the management of pain, fever and inflammation (Chen et al, 2005). They are believed to work through the inhibition of at least 2 variations of cyclo-oxygenase (COX-1 and COX-2) thus inhibiting prostaglandins synthesis (Mahalakshmi et al., 2010).

Aloe vera is one of the most popular plants used in alternative medicine and is chemically composed of anthraquinone, polysaccharide and carbohydrate (Vinson et al., 2005). It is used for the treatment of ulcer, hepatitis, neoplasms and wound. It has also been reported that the plant possess anti-inflammatory properties and antigenotoxic , chemopreventive, antioxidative and antiviral effects (Kim and Lee,1997, Zhang and Tizard, 1996, Kim et al., 1999, Lee et al.,2000; Hu et al.,2003). Aloe vera is used for liver problems and as a hepatic stimulant (Alqasoumi et al., 2008; Rajasekaran and Sathishsekar, 2007).

Honey a product of honeybees is used as a medicine in many cultures times and is known to exhibit a broad spectrum of activities including antiviral, antibacterial, antioxidant activity and immune-stimulant properties (Molan, 2002; Mato et al., 2003; Mabrouk et al., 2004; Aljadi and Kamaruddin, 2004 ; Khadr, et al., 2007). Ibuprofen is widely abused by students, labourers and artisans in Nigeria because of its analgesic affect this study was designed to determine the effects of Aloe vera extract and honey against ibuprofen induced liver toxicity in rats.

\section{Materials and Methods}

\section{Collection, identification and preparation of Aloe vera plant extract}

Aloe vera plant were obtained from a commercial botanical garden in Maiduguri and the fresh leaves were identified and authenticated by Dr. S.S. Sanusi (Plant Taxonomist) of the Department of Biological Sciences, University of Maiduguri, Borno state. A total of $500 \mathrm{~g}$ of the fresh leaves were harvested and squeezed to obtain a jelly sap that was then preserved in a refrigerator at $20^{\circ} \mathrm{C}$.

\section{Preparation of Honey}

Fresh, pure and undiluted honey was obtained from a bee hive directly. It was then sieved with a clear mesh to remove unwanted particles and stored at room temperature until used.

Preparation of Ibuprofen solution

Capsules containing $400 \mathrm{mg}$ of ibuprofen were obtained commercially from a pharmaceutical store located in the University of Maiduguri student centre. The drug was dissolved in $10 \mathrm{ml}$ of normal saline to form the stock solution 
The effects of Honey and Aloe Vera extract on Ibuprofen Induced Liver Damage in rats.

Animals: This study was carried out in the Department of Human Anatomy, University of Maiduguri, Nigeria. A total of twenty five (25) adult male Albino rats weighing 100- 150g were used for the study. The rats were obtained from the Department of Pharmacology, University of Jos, Nigeria and were maintained in the Animal holdings of the Department of Human Anatomy, University of Maiduguri, Nigeria. After an acclimatization period of two weeks the rats were individually indentified by color tattoo and weighed. The rats were then kept in plastic cages at room temperature and provided with rat pellets (Sanders Seepc, Nig. Ltd) and water ad libitum. The rats were cared for according to the Guiding Principles for the Care and Use of Animals based on the Helsinki Declaration as amended by World Medical Assembly, Venice, Italy (Declaration of Helsinki, 1996).

Experimental Protocol: The twenty five adult male albino rats were divided using simple random sampling into five groups (I, II, III, IV and V) of five rats each. Rats in group I served as control and were administered normal saline equivalent to the highest dosed group, rats in group II were administered $100 \mathrm{mgkg}^{-1}$ of ibuprofen, rats in group III were administered $100 \mathrm{mgkg}^{-1}$ of ibuprofen and $10 \mathrm{gkg}^{-1}$ of Aloe Vera extract, rats in group IV were administered $100 \mathrm{gkg}^{-1}$ of ibuprofen and $10 \mathrm{gkg}^{-1}$ of honey while rats in group V were administered with $100 \mathrm{mgkg}^{-1}$ of ibuprofen, $10 \mathrm{gkg}^{-1}$ of Aloe vera extract and $10 \mathrm{gkg}^{-1}$ of honey. The administration was by the oral method and it was for a period of 14 days.

At the end of the experimental period the rats were then sacrificed and the blood obtained was subjected to biochemical investigations. The liver was then harvested, trimmed of any adherent tissue, the wet weight taken and preserved in Bouin's fluid for subsequent histopathological examination.

Biochemical analysis: Blood collected from the animals by transaction of the jugular vein were put into sterile bottles and centrifuged at a rate of 12,000 revolutions per minute (rpm) for 10 minutes. The clear serum obtained was separated and labeled for the analyses of the serum levels of Aspartate minotransferases (ASAT), Alanine aminotransferases (ALAT) and Alkaline phosphatase (ALP). The analyses were carried out at the Department of Chemical Pathology, University of Maiduguri, Maiduguri.

Tissue Processing: The liver tissues obtained were fixed in Bouin's fluid for $8 \mathrm{hrs}$, dehydrated, embedded in paraffin wax. From each specimen, $5 \mu \mathrm{m}$ serial sections were cut, with two sections separated by $20 \mu \mathrm{m}$ on each glass slide. All sections were stained with Haematoxylin and Eosin.

Statistical Analysis: The data obtained were recorded and analyzed for Duncan multiple comparison tests using statistical package (GraphPad Instat version 4.0). The results were expressed as mean \pm standard error of mean (SEM) and $\mathrm{p}$ value of less than 0.05 was considered significant.

\section{Results}

\section{Effects of the administration of Ibuprofen, Aloe vera extract and Honey on mean liver weight.}

The result showed a slight increase in the liver weight of the rats that were administered with 100 $\mathrm{mgkg}^{-1}$ of ibuprofen when compared to the control group that was administered with normal saline only. The same results were also observed in the rats that were administered with $10 \mathrm{gkg}^{-1}$ of Aloe Vera extract / Honey and the combination of both when compared with the ibuprofen treated group (Table 1).

Table 1: The effect of the administration of Ibuprofen, Aloe Vera extract and honey on mean liver weight and biochemical parameters.

\begin{tabular}{lcccclll}
\hline Groups & $\begin{array}{c}\text { Doses administered } \\
\text { Ibuprofen } \\
\left(\mathbf{m g k g}^{-1}\right)\end{array}$ & $\begin{array}{c}\text { Aloe Vera } \\
\left(\mathbf{g k g}^{-1}\right)\end{array}$ & $\begin{array}{c}\text { Honey } \\
\left(\mathbf{g k g}^{-1}\right)\end{array}$ & $\begin{array}{c}\text { Parameters measured } \\
\text { Liver weight } \\
(\mathbf{m g})\end{array}$ & $\begin{array}{l}\text { ASAT } \\
\left(\mathbf{I U L}^{-1}\right)\end{array}$ & $\begin{array}{l}\text { ALAT } \\
\left(\mathbf{I U L}^{-1}\right)\end{array}$ & $\begin{array}{l}\text { ALP } \\
\left(\mathbf{I U L}^{-\mathbf{1}}\right)\end{array}$ \\
\hline I & 0 & 0 & 0 & $4.35 \pm 0.22$ & $55.00 \pm 1.04$ & $20.50 \pm 3.08$ & $173.50 \pm 2.04$ \\
II & 100 & 0 & 0 & $4.40 \pm 0.18$ & $70.00 \pm 1.41^{* * *}$ & $29.50 \pm 2.12^{*}$ & $184.50 \pm 3.54 * *$ \\
III & 100 & 10 & 0 & $4.49 \pm 0.67$ & $81.00 \pm 2.82^{\mathrm{a}}$ & $30.00 \pm 1.41$ & $190.50 \pm 7.78$ \\
IV & 100 & 0 & 10 & $4.67 \pm 1.04$ & $70.00 \pm 1.41$ & $23.00 \pm 2.82$ & $173.00 \pm 8.49^{\mathrm{a}}$ \\
V & 100 & 10 & 10 & $4.45 \pm 0.01$ & $63.00 \pm 5.65$ & $29.50 \pm 3.54$ & $132.00 \pm 5.66^{\text {a a a }}$ \\
\hline
\end{tabular}

Results are presented as mean \pm SEM; *significance relative to control and at $\mathrm{P}<0.05$ : ${ }^{\text {asignificance relative to }}$ Ibuprofen control dosed group $\mathrm{P}<0.05$. ASAT $=$ Aspartate Aminotransaminases, ALAT $=$ Alanine Aminotransaminases and ALP $=$ Alkaline Phosphatase. $\mathrm{N}=5$

\section{Effects of the administration of Ibuprofen, Aloe vera extract and Honey on Biochemical parameters.}

The effects of the administration of Ibuprofen, Aloe vera extract and honey on biochemical parameters are presented in Table 1. Biochemical analysis of blood showed a significant increase $(\mathrm{P}<0.05)$ in the levels of ASAT, ALAT and ALP in the ibuprofen treated rats when compared to the control rats. Administration of 10 $\mathrm{gkg}^{-1}$ of Aloe vera extract against ibuprofen induced liver damaged mostly caused significant $(P<0.05)$ increases in the serum levels of ASAT, ALAT and ALP when compared to the ibuprofen treated rats. Administration of $10 \mathrm{gkg}^{-1}$ of honey showed a slight and significant decrease in the serum levels of ASAT, ALAT and ALP when compared to the ibuprofen treated rats while the administration of a combine dose of $10 \mathrm{gkg}^{-1}$ of Aloe vera extract and honey also showed slight decreases in the serum levels of ASAT, ALAT and ALP when compared to the ibuprofen treated rats. 
The effects of Honey and Aloe Vera extract on Ibuprofen Induced Liver Damage in rats.

\section{Histological findings}

Liver sections from the control group showed normal liver parenchyma with the central vein clearly seen along with bile ducts and hepatic arteries. The hepatocytes were neatly arranged in anastomosing plates with the sinusoids radiating from the central vein (Fig. 1). Severe dilatation of blood vessels, necrosis of vascular connective tissues and wide spread areas of vacuolar degeneration were the histopathological changes observed in the liver of rats administered $100 \mathrm{mgkg}^{-1}$ Ibuprofen (Fig.2). Severe congestion and dilatation of blood vessels were the changes observed in rats administered with $10 \mathrm{gkg}^{-1}$ Aloe vera and $100 \mathrm{mgkg}^{-1} \mathrm{Ibuprofen}^{-1}$ (Fig.3) while rats treated with $10 \mathrm{gkg}^{-1}$ honey and100 mgkg ${ }^{-1}$ Ibuprofen presented with marked edema and bile duct hyperplasia (Fig.4), multi-focal blood channels and hepatic necrosis were the histopathological changes associated with the administration of $10 \mathrm{gkg}^{-1}$ honey, $10 \mathrm{gkg}^{-1}$ Aloe vera and $100 \mathrm{mgkg}^{-1}$ Ibuprofen (Fig.5).

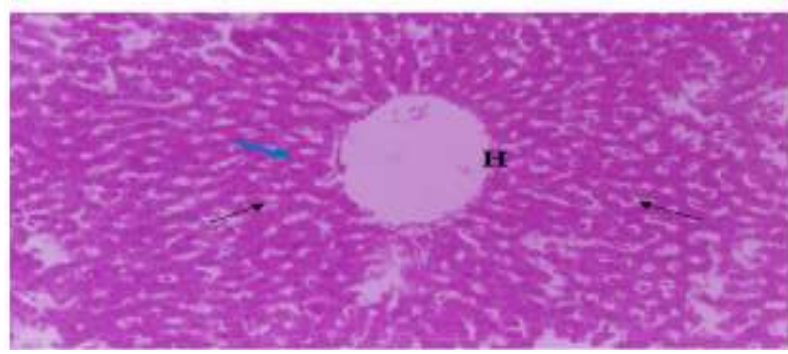

Fig. 1 Photomicrograph of control rat liver showing normal hepatocytes (arrow blue), sinusoids (arrow) and central vein $(\mathrm{H}) \mathrm{H} \& \mathrm{E}$ x 200.

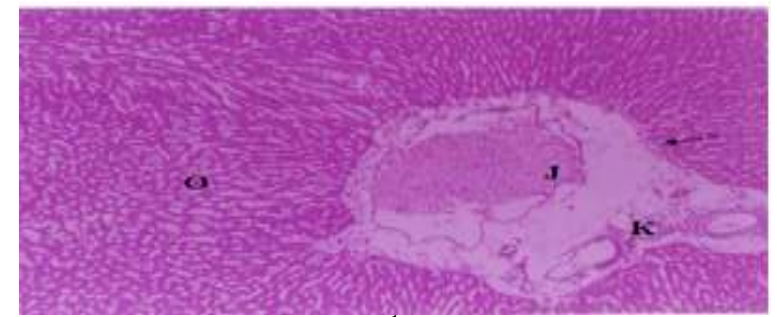

Fig. 2: Photomicrograph of rat liver treated with $100 \mathrm{mgkg}^{-1}$ Ibuprofen showing severe dilation of blood vessel (arrow) necrosis of vascular connective tissues (K) and wide spread areas of vacuolar degeneration (O), H \& E x200.

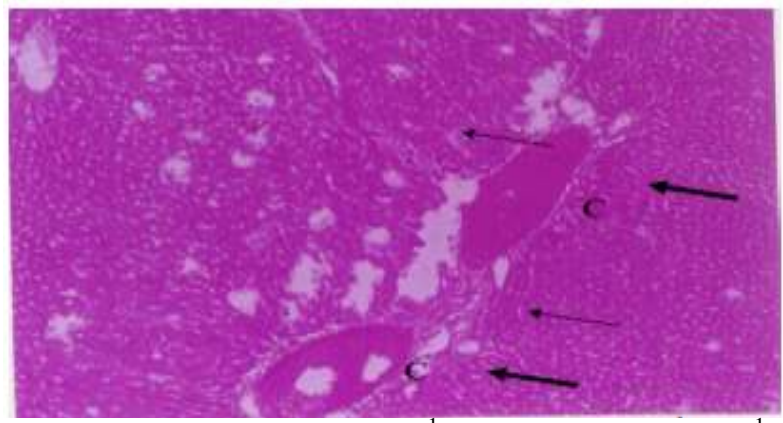

Fig. 3: Photomicrograph of rat liver treated with $10 \mathrm{gkg}^{-1}$ Aloe Vera $+100 \mathrm{mgkg}^{-1}$ Ibuprofen showing severe congestion (C), fibrous connective tissues (arrow) and dilation of blood vessels (thick arrow) H \& E x200.

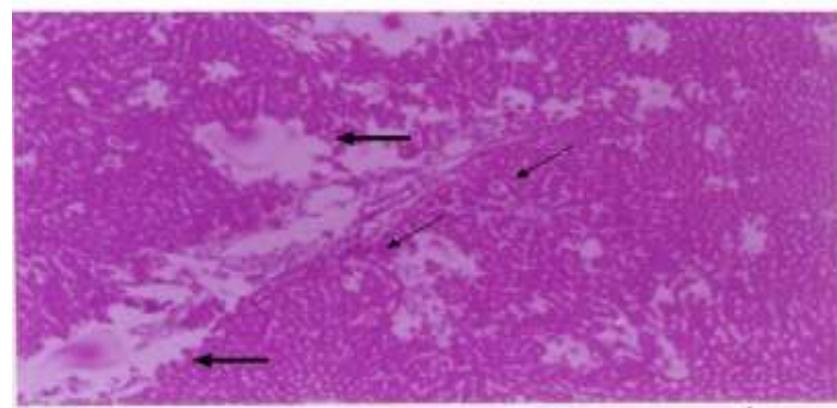

Fig. 4: Photomicrograph of rat liver treated with $10 \mathrm{gkg}^{-1}$ honey $+100 \mathrm{mgkg}^{-1}$ Ibuprofen showing edema (thick arrow), bile duct hyperplasia (thin arrow) H \& E x200. 


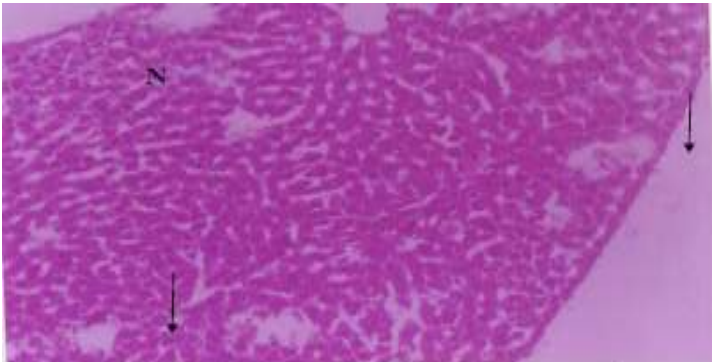

Fig.5: Photomicrograph of rat liver treated with $10 \mathrm{gkg}^{-1}$ honey $+10 \mathrm{gkg}^{-1}$ aloe Vera $+100 \mathrm{mgkg}^{-1} \mathrm{Ibuprofen}$ showing multi-focal blood channels (arrows) and hepatic necrosis (N) H \& E x200.

\section{Discussion}

In the assessment of liver damage certain biomarkers of hepatotoxicity are measured and one of such biomarkers are enzyme levels such as ASAT and ALAT because liver damage arising from necrosis or membrane damage normally releases the enzymes into circulation; therefore, measurement of these enzymes in serum gives an indication of the health status of the liver. High levels of ASAT indicate liver damage, as that due to viral hepatitis as well as cardiac infarction and muscle injury. ALAT catalyses the conversion of alanine to pyruvate and glutamate, and is released in a similar manner. It is known that an increase in the enzymatic activity of ALAT and ASAT in the serum directly reflects a major permeability or cell rupture, and thus ALAT is more specific to the liver, and is thus a better parameter for detecting liver injury (Benjamin, 1978 ; Wittwer and Bouhmwald, 1986). An increase in ASAT and ALAT, a hepatospecific enzyme that is principally found in the cytoplasm of rats following administration of a hepatotoxin is attributed to the increased release of enzymes from the damaged liver parenchymal cells (Benjamin, 1978; Ringler and Dabich, 1979; Singh, 1980 ; Garba, et al.,2009). The elevated level of alkaline phosphatase an enzyme produced in the liver, bone and placenta indicates liver injury or bile duct obstruction as a result of ibuprofen administration. Liver injuries are mostly caused by interference with the metabolic pathways essential for parenchymal cell intergrity. They lead to diversion, competitive inhibition or structural distortion of molecules essential for metabolism or to selectively blockade of key metabolic pathways required to maintain the intact hepatocyte. The biochemical and physiological lesions induced by these agents lead to degenerative changes such as steatosis, necrosis or both (Garba et al.,2006).

Oedema in this result denotes excess plasma fluid in the interstitium which normally causes an expansion in the intracellular matrix and a major local manifestation of acute inflammation in dividing resident of lymphocytes or macrophages (Kumar, et al., 2004). Serum ASAT, ALAT is the most sensitive biomarkers used in the diagnosis of liver diseases (Pari and Kumar, 2002). During hepatocellular damage, varieties of enzymes normally located in the cytosol are released into the blood flow. Their quantification in plasma is useful biomarkers of the extent and type of hepatocellular damage (Pari and Murugan, 2004). Serum ALAT catalyses the conversion of alanine to pyruvate and glutamate, and is released in a similar manner.

Therefore, serum ALAT is more specific to the liver, and is thus a better parameter for detecting liver injury (Williamson et al., 1996). In conjunction with the reports of (Cho et al., 2009; Hegde and Joshi, 2009; Kim et al., 2010), data from the present study showed that $\mathrm{CCl}_{4}$ caused hepatic damage with a significant increase in serum levels of ASAT and ALAT. Serum ALP level is also related to the status and function of hepatic cells. $\mathrm{CCl}_{4}$ administration in the present study also caused significant increase in the serum ALP which may be due to increased synthesis in presence of increasing biliary pressure (Moss and Butterworth, 1974).

The distortion of the radial arrangement of the sinusoids from the central vein, the distortion of the hexagonal shape of the hepatocytes with evidence of hepatic necrosis may be due to the cleaving of sialic acid by the enzyme sialidase from the haemoglobin-free erythrocytes, plasma and the liver, thus exposing the liver to the damage noticed (Wilson et al., 2011). The reduction in some of the damage caused by ibuprofen administration may be attributed to the beneficial effect of honey in the prevention of hepatic damage induced by obstruction of the common bile duct (Erguder et al., 2008) who suggested that honey supplementation might gives beneficial results.

\section{Acknowledgement}

We wish to acknowledge the technical assistance of Ibrahim Wiam and Ephraim Ayuba of the Departments of Veterinary Anatomy and Human Anatomy, University of Maiduguri, Nigeria.

\section{References}


The effects of Honey and Aloe Vera extract on Ibuprofen Induced Liver Damage in rats.

[1] Aljadi, A.M. and M.Y. Kamaruddin, (2004). Evaluation of the phenolic contents and antioxidant capacities of two Malaysian floral honeys. Food Chemistry. 85: 513-518.

[2] Alqasoumi, S. I. Tawfik A. Al-Howiriny and Maged S. Abdel-Kader, (2008). Evaluation of the Hepatoprotective Effect of Aloe vera, Clematis hirsute, Cucumis prophetarum and Bee Propolis Against Experimentally Induced Liver Injury in Rats. International Journal of Pharmacology, 4: 213-217.

[3] Benjamin M. N, (1978). Outline of veterinary Clinical Pathology. University press. Iowa, pp. 229-232

[4] Chen H, Jacobs E, Schwarzschild M, McCullough M, Calle E, Thun M, Ascherio A (2005). "Non-steroidal anti-inflammatory drug use and the risk for Parkinson's disease.". Ann Neurol 58 (6): 963-7.

[5] Cho YK, Yun JW, Park JH, Kim HJ, Park DI, Sohn CI, Jeon WK, Kim BI,Jin W, Kwon YH, Shin MK, Yoo TM, Kang JH, Park CS. (2009). Deleterious effects of silymarin on the expression of genes controlling endothelial nitric oxide synthase activity in carbon tetrachloride treated rat livers. Life Sci., 12;85 (7-8): 281-290.

[6] Declaration of Helsinki, (1996). Amended by World Medical Assembly, Venice, Italy, 1983. Br. Med. J. 313(7070), 1448-1449

[7] Erguder BI, Kilicoglu SS, Namuslu M, Kilicoglu B, Devrim E, Kismet K, Durak I, (2008). Honey prevents hepatic damage Induced by obstruction of the common bile duct. World Journal of Gastroenterology, 14(23): 3729-3732.

[8] Garba, S. H. Sambo, N. and Bala , U. (2009). The Effect of the Aqueous Extract of Kohautia Grandiflora on Paracetamol Induced Liver Damage in Albino Rats. Nig. J. of Physiol. Sci. 24 (1): 17-23

[9] Garba , S.H. Prasad, J. and Sandabe, U.K. (2006). Histomorphological Effect of the Aqueous Root-Bark Extract of Ficus sycomorus (Linn) on the Liver and Kidney of Albino Rats . International Journal of Pharmacology, 2: 628-632.

[10] Hegde K, Joshi A B .(2009). Hepatoprotective effect of Carissa carandas Linn root extract against $\mathrm{CCl}_{4}$ and paracetamol induced hepatic oxidative stress. Indian J. Exp. Biol., 47(8): 660-667.

[11] $\mathrm{Hu}$ Y, Xu J, Hu Q (2003). Evaluation of antioxidant potential of aloe vera (aloe barbadensis miller) extracts. J. Agric. Food Chem. 51: $7788-7791$.

[12] Khadr, M. E. Karam A. Mahdy, Karima A. El-Shamy, Fatma A. Morsy, Salwa R. El-Zayat and Azza A. Abd-Allah, (2007). Antioxidant Activity and Hepatoprotective Potential of Black Seed, Honey and Silymarin on Experimental Liver Injuries Induced by $\mathrm{CCl}_{4}$ in Rats. Journal of Applied Sciences, 7: 3909-3917.

[13] Kim H Y, Kim J K, Choi J H, Jung J Y, Oh W Y, Kim D C, Lee H S, Kim Y S, Kang S S, Lee S H, Lee S M (2010). Hepatoprotective effect of pinoresinol on carbon tetrachloride-induced hepatic damage in mice. J. Pharmacol. Sci., 112(1):105112.

[14] Kim HS, Kacew S, Lee BM (1999).. In vitro chemopreventive effects of plant polysaccharides (Aloe barbadensis Miller, Lentinus edodes, Ganoderma lucidum and Coriolus versicolor). Carcinogenesis. 20: 1637-1640.

[15] Kim HS, Lee BM (1997). Inhibition of benzo[a]pyrene - DNA adduct formation by Aloe barbadensis Miller. Carcinogenesis. 18: 771-776.

[16] Kumar, Abbas, A. K. Fausto, N. (2004). Robbins and Cotran Pathologic Basis of Disease. 7th ed. Saunders Elsevier, Philadelphia, pp. 48-51.

[17] Lee KY, Weintraub ST, Yu BP (2000). Isolation and identification of a phenolic antioxidant from Aloe vera barbadensis. Free Radical Biol. Med. 28: 261-265.

[18] Mabrouk, G.M., S.F. Zohny, E.M.M. Ali, E.F. Ismail and S.S. Moselhy, (2004). Bee honey and Nigella sativa inhibit nitric oxide mediated cytochrome $\mathrm{C}$ release and down-regulation of connex in 43 induced by methyl nitrosourea in hepatic tissues of Sprague Dawely rats. Egypt J. Biochem., 22: 73-87.

[19] Mahalakshmi, R. P. Rajesh, N. Ramesh, V. Balasubramanian and V. Rajesh Kannan, (2010). Hepatoprotective Activity on Vitex negundo Linn. (Verbenaceae) by using Wistar Albino Rats in Ibuprofen Induced Model. International Journal of Pharmacology, 6: 658-663.

[20] Mato, I., J.F. Huidobro, J. Simal-Lozano and M.T. Sancho, (2003). Significance of nonaromatic organic acids in honey. J. Food Prot., 66: 2371-2376.

[21] Molan, P.C., (2002). Revival of honey as a medicine. Honeybee Sci., 23: 153-160.

[22] Moss D W, Butterworth P J (1974). Enzymology and Medicine. Pitman Medical, London, p. 139

[23] Pari L, Kumar A N (2002). Hepatoprotective activity of Moringa oleifera on antitubercular drug induced liver damage in rats. J. Med., 5: 171- 177 .

[24] Pari L, Murugan P. (2004). Protective role of tetrahydrocurcumin against erythromycin estolate-induced hepatotoxicity. Pharmacol. Res., 49(5):481-486

[25] Rajasekaran, S. and D. Sathishsekar, (2007). Therapeutic Evaluation of Aloe vera Leaf Gel Extract on Glycoprotein Components in Rats with Streptozotocin Diabetes . Journal of Pharmacology and Toxicology, 2: 380-385.

[26] Ringler, D.H. and L. Dabich, (1979). Hematology and Clinical Biochemistry. In: The Laboratory Rat. Vol.1, Baker, H.J., J.R. Lindsey and S. H. Weisbroth (Eds.) Academic Press. London. pp:105-118

[27] Singh, I. (1980). In: Textbook of Biochemistry and Human Biology. Talwar, G. P. (ed.), Prentice Hall of India, New Delhi. pp. 201-203

[28] Vinson JA, Kharrat HA, Andreoli L(2005). Effect of Aloe vera preparations on the human bioavailability of vitamins C and E. Phytomedicine. 12: 760-765.

[29] Williamson EM, Okpako DT, Evans FJ (1996). Selection, preparation and pharmacological evaluation of plant material, John Wiley, England, p.13

[30] Wilson JI, George BO, Umukoro GE (2011). Effects of honey on the histology of liver in adult Wistar rats Biology and Medicine, $3(1): 1-5$

[31] Wittwer, F. M. and Bohmwald, L. H. (1986). Manuel de Patologia Clinica Veterinaria. Valdivia Chile, pp; 53-93.

[32] Zhang L, Tizard IR (1996). Activation of a mouse macrophage cell line by acemannan: the major carbohydrate fraction from Aloe vera gel. Immunopharmacology. 35: 119-128. 